\title{
Public Housing and Social Capital in Australia
}

\author{
Jed Donoghue ${ }^{1}$ and Bruce Tranter ${ }^{2}$
}

(Received January 7, 2013 / Revised April 26, 2013 / Accepted April 29, 2013)

\begin{abstract}
This paper addresses the relationship between public housing tenure and social disadvantage. The research examines social capital levels among public tenants in Australia, concentrating on their level of interpersonal trust and confidence in a range of public institutions. Through multivariate analyses of national survey data it also profiles the social and political background of public housing tenants. Although public housing tenants have access to secure and affordable housing, they appear to be less trusting and 'happy' than private renters or homeowners, and exhibit less confidence in some institutions such as the Australian parliament, universities and the ABC (the Australian public television broadcaster). These results probably reflect the residualised nature of public housing in Australia and indicate that public tenants are likely to be 'alienated' from certain aspects of mainstream culture. However, public tenants have higher levels of confidence than homeowners in the Australian defence forces and trade unions. So public housing may 'shore up' confidence and social capital in some areas, and levels of trust would be lower if public housing was not available to disadvantaged citizens.
\end{abstract}

Key words: Public Housing, Social Capital, Australia

\section{Introduction}

This research examines levels of social capital among public housing tenants in Australia. We consider two key indicators of social capital-public tenants' levels of interpersonal trust and their confidence in a range of public institutions. We recognise that social capital is itself a contested concept that can provide an opportunity or reinforce disadvantage (Fukuyama, 1995: 10). Putnam (1995: 67) defines social capital as 'features of social life -networks, norms and trust-that enable participants to act together more effectively to pursue shared objectives'. However, for Bourdieu (1986) an important aspect of social capital is that it is transformable, with the potential to be converted into economic and social advantage. Bourdieu (1986: 248) defines social capital as the 'aggregate of the actual or potential resources which are linked to the possession of a durable network of more or less institutionalized relationships of mutual acquaintance or recognition'. Social capital therefore consists of 'social obligations' or connections that are 'convertible in certain conditions' into economic capital and social opportunities (Bourdieu, 1986: 243).

A range of factors determines the nature and form of social capital in a community. These factors include historical and cultural issues; flat or hierarchical social structures; family; education; built environment; residential mobility; economic inequalities and social class; the strength of civil society; and patterns of individual consumption and personal values (Putnam, 2000; Skocpol, 2003). When social capital is widely shared in a community it can be regarded as a 'public good', in the context where all members of the community have access to it. However, if particular groups control social networks, reciprocal norms and sanctions, then social capital corresponds more to a 'club' good or a resource for narrow self-interest. If social capital is limited or controlled by sectional interests it can have a negative effect on the development of human, cultural and financial capital, and restrict economic growth and employment opportunities for non-group members.

\section{Social Trust}

Social capital is based on networks, norms and social trust that facilitate the coordination and cooperation for mutual benefit, with interpersonal trust a central component. There are three

1) Honorary Research Associate, School of Sociology \& Social Work, University of Tasmania (Main author: jedonogh@utas.edu.au)

2) Associate Professor, School of Sociology \& Social Work, University of Tasmania (Corresponding author: Bruce.Tranter@utas.edu.au) 
main types of social capital according to Putnam (2000): bonding, bridging and linking social capital. Bonding social capital is characterised by strong bonds among family members or members of a particular cultural group. Bridging social capital is associated with weaker, less dense ties that crosscut work, friendships, and acquaintances from different groups. Linking social capital is related to connections between people with different levels of status or power, such as links between the political elite and the general public or between individuals from different social classes.

One way of measuring social capital is to gauge the extent that people think other people can be trusted (Tranter and Skrbis, 2009). Conceptulisations of trust range from the position that it is a vital part of reflexive encounters between individuals in contemporary societies (Giddens, 2000), to the notion that a culture of fear tends to flourish in trust-deficit societies (Furedi, 2005).

Job (2005) distinguishes between 'rational' and 'relational' notions of trust. Relational trust 'has ethical roots and is based on belief or faith in the goodness of others' (Job, 2005: 4). Also referred to as 'moralistic trust', it is conceived as a 'trusting disposition' learned during early socialisation (Job, 2005: 4). Rational trust on the other hand is strategic as it 'assumes that to trust presupposes consideration of information or knowledge about the other' (Job, 2005: 4). The latter involves weighing up information in order to calculate the risks of placing one's trust in others. The important point is that diminished trust in a community undermines social connections and civic mindedness.

\section{Public Housing}

The Commonwealth State Housing Agreement (CSHA) has been the primary policy instrument for public housing in Australia since 1945 and has provided the institutional, financial and policy frameworks within which social housing has developed and operated (Jones et al., 2007: 14). The first ten years of the CSHA was characterized by the post war construction of public housing properties. The policy changed in 1956 with a new focus on the sale of public housing stock to sitting tenants to promote homeownership. In 1973 concerns over poverty and unemployment led to the introduction of tighter eligibility criteria and a means test for public housing so that it targeted low-income earners.

The profile of public housing applicants and tenants has changed over time and the needs of public tenants are now more complex, with a higher prevalence of mental illness, disability and behavioural issues associated with multiple social disadvantages (Jones et al., 2007). In 2009 there were less than 420,000 social housing dwellings and over 173,456 applicants on public housing waiting lists in Australia (AIHW, 2010). Public housing is now generally regarded as the 'tenure of last resort' (Watt, 2006).

The focus of public housing allocation is on the provision of assistance to the most disadvantaged, such as the unemployed, disabled and lone parents. The increasing concentration of the most disadvantaged people in public housing estates has social costs in terms of stigmatization, poor employment prospects and intergenerational poverty (Atkinson and Jacobs, 2008). As State governments struggled to provide a coherent approach to the housing needs of the disadvantaged, many low-income earners experience housing stress in the private rental market, and homeownership has become difficult to achieve. It is important to note that successive Australian governments have generally promoted policies that reinforce homeownership, as the majority of the population is engaged in homeownership as either owners or buyers (Troy, 2000).

In the next section of this paper we will focus on an empirical examination of the social background of public housing tenants, and explore social capital among public housing tenants compared to other housing tenures.

\section{Data and Method}

We employ multivariate statistical methods to analyze secondary data from a large national survey. The aim is to provide representative findings on the social background and attitudes of tenants in a range of housing tenures, particularly public housing. The advantage of this approach is that our findings are generalisable to the adult population of Australia and the multivariate approach allows us to statistically 'control' for several potentially confounding factors when examining relationships between different housing tenures and aspects of social capital.

This research is based upon the analysis of survey data from the 2003 Australian Survey of Social Attitudes (AuSSA), a large sample of Australian adults aged 18 and above (Gibson et al., 2004). The AuSSA is a unique data source well suited to our purpose as it not only allows us to access important socio-demographic data, but also data relating to a range of social and political attitudes and self-assessed health. The 2003 AuSSA is the first in a biennial series of cross sectional surveys administered by a team of researchers through the Australian National University and was obtained from the Australian Social Science Data 
Table 1. Social and Political Background of Public Housing Tenants (\%)

\begin{tabular}{|c|c|c|c|c|}
\hline & Public Housing & Private Rental & Mortgage & Owners \\
\hline Men & 3.3 & 11.9 & 38.2 & 35.2 \\
\hline Women & 4.6 & 11.9 & 33.6 & 38.2 \\
\hline \multicolumn{5}{|l|}{$X^{2} p=.010$} \\
\hline Aged $18-29$ & 3.6 & 22.7 & 22.6 & 7.7 \\
\hline Aged $30-49$ & 3.6 & 13.1 & 58.7 & 18.7 \\
\hline Aged $50+$ & 4.4 & 5.1 & 16.9 & 71.7 \\
\hline \multicolumn{5}{|l|}{$X^{2} p<.001$} \\
\hline Indigenous Australian & 24.2 & 13.6 & 25.8 & 7.6 \\
\hline Non-Indigenous & 3.6 & 11.9 & 36.3 & 36.7 \\
\hline \multicolumn{5}{|l|}{$X^{2} p<.001$} \\
\hline Education less than year 10 & 7.7 & 9.1 & 21.0 & 54.9 \\
\hline Completed Grade 10 & 5.3 & 11.9 & 36.7 & 38.8 \\
\hline Completed Grade 12 or above & 2.4 & 12.5 & 40.5 & 30.0 \\
\hline \multicolumn{5}{|l|}{$X^{2} p<.001$} \\
\hline Personal Income $\$ 0-20,799$ & 7.2 & 11.4 & 22.4 & 44.4 \\
\hline$\$ 20,800-31,199$ & 3.8 & 15.9 & 37.1 & 29.1 \\
\hline Above $\$ 31,199$ & 0.4 & 11.1 & 50.4 & 30.2 \\
\hline \multicolumn{5}{|l|}{$X^{2} p<.001$} \\
\hline \multicolumn{5}{|l|}{ Self Assessed Class } \\
\hline No Class location & 14.8 & 19.4 & 19.6 & 34.1 \\
\hline Working Class & 4.6 & 13.3 & 37.6 & 33.2 \\
\hline Upper and Middle & 1.0 & 9.1 & 38.2 & 40.5 \\
\hline \multicolumn{5}{|l|}{$X^{2} p<.001$} \\
\hline Home Occupancy - Single & 10.1 & 20.6 & 22.4 & 45.4 \\
\hline Other occupancies & 3.1 & 10.8 & 37.8 & 35.5 \\
\hline \multicolumn{5}{|l|}{$X^{2} p<.001$} \\
\hline Single & 5.7 & 21.0 & 21.2 & 13.3 \\
\hline Separated & 6.5 & 26.9 & 38.0 & 20.4 \\
\hline Divorced & 14.7 & 17.5 & 33.3 & 29.1 \\
\hline Widowed & 7.8 & 5.3 & 5.8 & 77.7 \\
\hline Married/de facto & 1.6 & 6.6 & 45.1 & 45.4 \\
\hline \multicolumn{5}{|l|}{$X^{2} p<.001$} \\
\hline Live Inner Metropolitan Area & 4.1 & 15.6 & 36.5 & 32.2 \\
\hline Live elsewhere & 3.8 & 10.5 & 35.8 & 38.3 \\
\hline \multicolumn{5}{|l|}{$X^{2} p<.001$} \\
\hline \multicolumn{5}{|l|}{ State } \\
\hline New South Wales & 3.8 & 12.0 & 33.9 & 38.7 \\
\hline Victoria & 1.8 & 12.3 & 32.8 & 39.2 \\
\hline Queensland & 5.4 & 12.5 & 38.0 & 34.2 \\
\hline South Australia & 6.0 & 10.2 & 37.1 & 36.0 \\
\hline Western Australia & 3.6 & 10.2 & 44.0 & 30.8 \\
\hline Tasmania & 3.9 & 12.6 & 35.4 & 42.5 \\
\hline \multicolumn{5}{|l|}{$X^{2} p<.001$} \\
\hline \multicolumn{5}{|l|}{ Political Party Identification } \\
\hline Coalition parties & 1.3 & 9.0 & 35.8 & 45.8 \\
\hline Labor Party & 6.5 & 11.5 & 35.8 & 37.5 \\
\hline Other party & 1.9 & 21.2 & 36.6 & 24.8 \\
\hline No party & 4.7 & 12.8 & 37.0 & 26.9 \\
\hline$X^{2} p<.001$ & & & & \\
\hline
\end{tabular}

Note: 'Other' tenure category of boarders and living at home excluded.

Source: Australian Survey of Social Attitudes (2003). 
Archive. The mail out, mail back survey was administered to respondents selected from the Australian electoral roll (sampling frame) using a systematic sampling strategy. The sample was also stratified so that the number of respondents from each state and territory is approximately proportionate to their respective population size. The AuSSA has a response rate of $44 \%$ and sample size of 4,270 (see Gibson et al.(2004) for further details )$^{1)}$. Given the sample was drawn systematically from the electoral roll, on the basis of probability theory (de Vaus, 2002) we are confident that the results from the AuSSA should be representative of the population of Australians aged 18 and over. The software used was SAS version 9.2. One of the limitations of the data is that it does not measure several components of social capital, e.g. levels of reciprocity and levels of informal participation. Although we do not control for personal characteristics, we do control for correlates of class, such as education and income levels.

We first present the results of a series of cross tabulations to show the background characteristics of those living in various housing tenures (Table 1). We then use binary and ordered logistic regression analysis, presenting odds ratios to examine associations between our dependent and independent variables in a multivariate context. We also provide asterisks to signify levels of statistical significance based upon inferential tests (i.e. Wald tests) to estimate the representativeness of the findings among our 'population' of Australians aged 18 and over (Tables 2-4). By adopting a multivariate approach we are able to estimate the net effects of the independent variables on the dependent variables (described below), while controlling for correlations between the independent variables.

Odds ratios are shown here to facilitate the interpretation of the regression estimates (see Agresti and Finlay(1997: 599-606)). Odd ratios (OR) indicate the strength of the associations between independent and dependent variables. OR of greater magnitude than 1 signify positive associations and those less than unity suggest negative associations. For example, in Table 2, the OR of 1.88 for those with less than high school education, suggests they are 1.9 times as likely as the reference category (i.e. those educated to grade 12 or above), to live in public housing rather than other tenures. OR less than 1 , such as 0.74 for the $18-29$ age cohort indicates that this cohort is 1.35 times less likely than the

1) The AuSSA includes a weighting variable to adjust the sample to reflect population parameters on the basis of age, sex and education level (see Gibson et al.(2004)). We apply the weighting variable for all analyses shown here.
Table 2. Social and Political Background of Public Housing Tenants (odds ratios)

\begin{tabular}{|c|c|}
\hline & Public Housing \\
\hline Men & 0.99 \\
\hline Women & 1 \\
\hline \multicolumn{2}{|l|}{ Aged } \\
\hline $18-29$ & 0.74 \\
\hline $30-49$ & 1.03 \\
\hline Aged 50 and over & 1 \\
\hline Indigenous Australians & $4.37 * * *$ \\
\hline Non-Indigenous & 1 \\
\hline \multicolumn{2}{|l|}{ Education } \\
\hline Less than High School & $1.88^{*}$ \\
\hline Completed Grade 10 & 1.45 \\
\hline Grade 12 or above & 1 \\
\hline \multicolumn{2}{|l|}{ Personal Income } \\
\hline$\$ 0-20,799$ & $10.31 * * *$ \\
\hline$\$ 20,800-31,199$ & $6.20 * * *$ \\
\hline Above $\$ 31,199$ & 1 \\
\hline \multicolumn{2}{|l|}{ Self Assessed Class } \\
\hline No Class location & $5.95 * * *$ \\
\hline Working Class & $2.64 * * *$ \\
\hline Upper and Middle & 1 \\
\hline Single Occupant Home & $1.56 \dagger$ \\
\hline Other occupancies & 1 \\
\hline Married & $0.29 * * *$ \\
\hline Other marital status & 1 \\
\hline Live in Inner Metropolitan area & $1.52 *$ \\
\hline Live elsewhere & 1 \\
\hline Live in Victoria & $0.37 * * *$ \\
\hline Live in other state/territory & 1 \\
\hline \multicolumn{2}{|l|}{ Party Identification } \\
\hline Labor Party & $3.54 * * *$ \\
\hline No Party Identification & $2.22 * *$ \\
\hline Other Party Identification & 1 \\
\hline Health scale & 0.973 \\
\hline Happiness scale & $0.894 * *$ \\
\hline Nagelkerke $\mathrm{R}^{2}$ & .31 \\
\hline $\mathrm{N}$ & $(3,753)$ \\
\hline
\end{tabular}

Notes: $\dagger \mathrm{p}<.1 ; * \mathrm{p}<.05 * * \mathrm{p}<.01 * * * \mathrm{p}<.001$

Source: Australian Survey of Social Attitudes (2003).

$50+$ reference group to live in public housing (i.e. $1 \div 0.74=1.35$ ).

In Table 2 housing tenure is operationalised as a dichotomous dependent variable with binary logistic regression analysis ( $1=$ public housing; $0=$ other housing tenures). The independent variables examined in Table 2 are age, sex, education, income, 
Table 3. Interpersonal Trust and Confidence in Institutions by Housing Tenure (odds ratios)

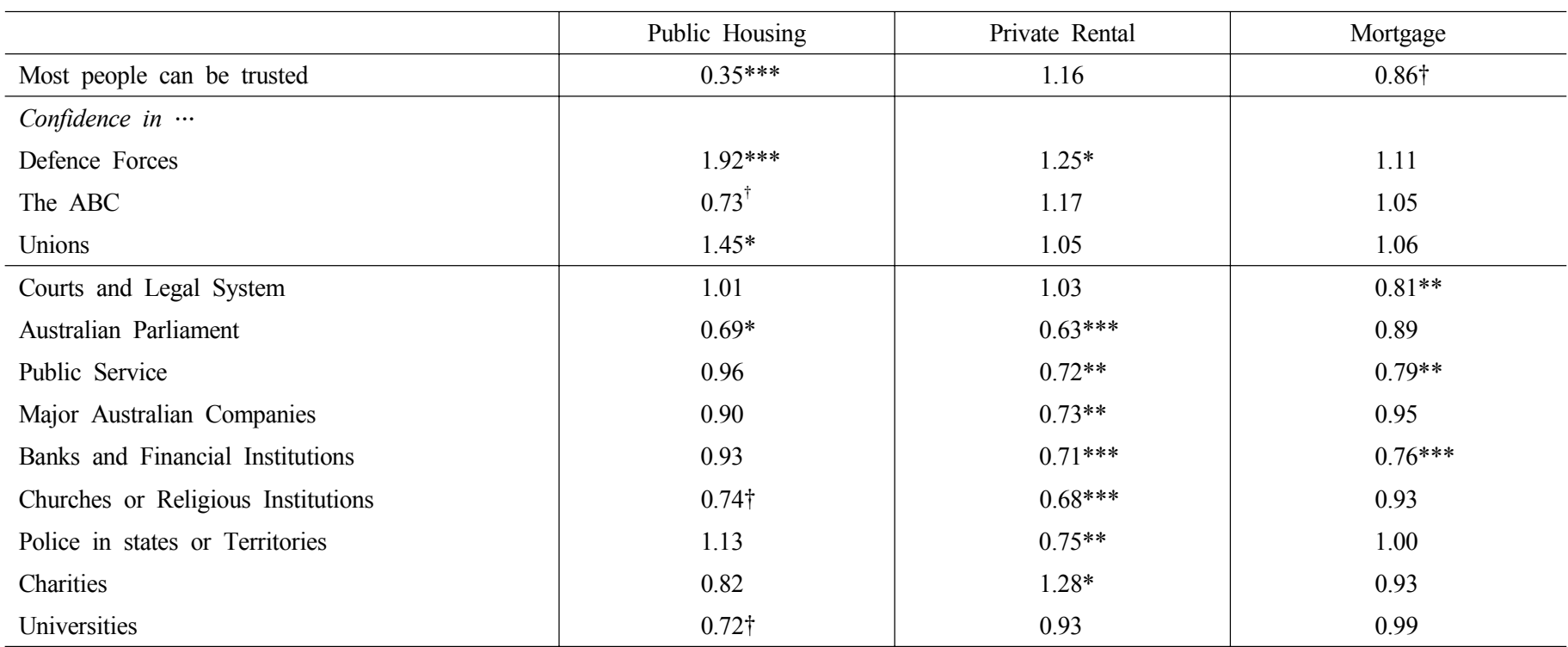

Notes: Reference category is homeowners + 'Other' category. Estimates control for sex, age, education, personal income, location and state. $\dagger \mathrm{p}<.1 ; * \mathrm{p}<.05 ; * * \mathrm{p}<.01 ; * * * \mathrm{p}<.001$

Source: Australian Survey of Social Attitudes (2003).

marital status, single occupancy household, self-assessed class location and political party identification. Two additional independent variables-self-rated scales-are also included in the regression model in Table 1 to measure self-assessed health ('How would you rate your health in general'; Responses: 4 Excellent, 3 Good, 2 Fair, 1 Poor) and happiness ('All in all, how happy are you with your life these days?' measured on a 10-point scale ranging from 0 extremely unhappy, to 10 extremely happy). While health status measured in this way is based on respondents' own assessments and cannot fully capture the multidimensionality of health, it has been employed extensively in studies of health status and serves as a useful proxy for psychological and biological dimensions of health (see Burstrom and Fredlund (2001)). We also model several dependent variables in Table 3 using ordered logistic regression with the estimates controlled for sex, age, education level, personal income, location and state. The standard r-squared statistic is not produced with logistic regression. Rather, pseudo-r-squared statistics (for example Nagelkerke $R^{2}$ ) are appropriate substitute measures of $\mathrm{R}^{2}$ for logistic regression.

\section{Analysis}

We begin our analysis by considering the social background of housing tenure (concentrating upon public housing) in several cross tabulations, presenting percentages and the results of chi-squared $\left(X^{2}\right)$ tests of statistical independence (Table 1).
Concentrating upon the first column of results in Table 1, we can see that indigenous Australians are much more likely than nonindigenous Australians to live in public housing. They are also very unlikely to own their own home. Those with less than 10 years of education are more likely to live in public housing, as are people on low incomes, those who do not identify with any social class, single occupant households, divorced or widowed people and Labor party identifiers.

Public tenants are more likely to be unemployed, employed on a casual or part time basis due to social housing allocation policies that target disadvantaged people. It is no surprise that those on lower incomes live in public housing as it is targeted at people in receipt of Commonwealth pensions or benefits. When public tenants do gain full time employment, they are often 'encouraged' to move to private rental or homeownership.

We now consider the social and political background of public housing tenure using logistic regression analysis in order to statistically control for correlations between the independent variables. As the dependent variable - living in public housing versus other tenures - is dichotomous, we use binary logistic regression in the analyses presented in Table 2 (see Long (1997)). Housing tenure is modeled on the basis of our independent variables-sex, age, secondary educational attainment, self-assessed social class location, size of household, personal income (we use the income categories provided by the AuSSA researchers), political party identification and marital status. We also control 
for respondents' self-assessed health and happiness in the regression model. As these are multiple regression models, the odds ratios presented are net of, or control for, the impact of all other independent variables in the regression equation.

In the multivariate case, no statistically significant gender or age differences are apparent at the $95 \%$ level of statistical significance (Table 2). However, even holding constant other social background factors, Indigenous Australian are over four times as likely as other Australians to live in public housing! Those with less than 10 years of education are twice as likely (OR 1.9) as those who have completed year 12 to live in public housing, while low-income earners (less than $\$ 20,800$ ) are ten times as likely as those earning over $\$ 31,200$ to live in public housing. Class is also an important factor distinguishing tenure. Those who do not identify with any social class are six times as likely as the middle class to be public tenants, while the likelihood of working class people to live in public housing is almost three times that of the middle class. Living in an inner metropolitan area is linked with public housing, while Victorians are approximately three times less likely than those in other states to live in public housing. Marital status is also associated with housing tenure, with married people three times less likely than others to live in public housing.

Political party affiliation is also associated with housing tenure. Labor party identifiers are more than three times as likely as Coalition or other party affiliates to live in public housing. Other results (not shown here) indicate a lower level of political 'interest' among public tenants, which is at least partly related to the social characteristics of those living in public housing, as educational achievement is an important correlate of political interest, and both are positively associated with knowledge of political processes and institutions (Tranter, 2007). Goot (2002: 43) claims there has been a general 'decline in the reputation of politicians for ethics and honesty'; 'electoral cynicism around the credibility of election promises' and 'a weakening attachment to party' are likely to be relevant factors here.

When we control for other socio-economic factors, single occupancy is not an important correlate of public housing, although public tenants are less happy with their lives than homeowners. In our full regression model presented in Table 2, the health scale is non-significant at the $95 \%$ level. However, in separate analyses (not shown) we found living in public housing to be associated with poorer health status, holding constant important correlates of health including age, sex, education and income, marital status, location and state. While health status is mediated through social class and contributes strongly to happiness, taken as a whole, these results provide strong empirical evidence that public housing is negatively associated with tenants' health, happiness and overall life satisfaction.

In the next set of analyses shown in Table 3 we examine various aspects of social capital by housing tenure (i.e. using ordered logistic regression analyses). We draw upon a range of indicators of social capital, including trust in others and confidence in government and other institutions. In these analyses, indicators of social capital are dependent variables and housing tenures are independent. We examine the relationship between housing tenure and some important correlates of social capital, beginning with a question on interpersonal trust: 'Generally speaking, would you say that most people can be trusted or that you can't be too careful in dealing with people?' We also control for a range of social background factors, including age, sex, education, personal income, location (i.e. city versus other) and state, so that the findings are expected to be robust. These results suggest that public tenants experience very high levels of interpersonal mistrust. Public tenants are almost three times (i.e. $1 \div 0.35=2.86$ ) less trusting of other people than are homeowners. They also have less confidence in the Australian parliament than homeowners, while the results for the $\mathrm{ABC} \mathrm{TV}$, churches and universities are also negative, but only statistically significant at the $90 \%$ level. On the other hand, public tenants have more confidence than homeowners in the Australian defence forces and trades union in contrast to the other social institutions examined here.

\section{Discussion}

The public housing sector comprises a small (less than 5\%), but important component of the housing market. Public housing tenants exhibit lower levels of interpersonal trust than private renters or homeowners even after holding constant differences in their age, sex, education, location, the state they live in and their personal income level. The allocation of public housing to the most disadvantaged applicants inevitably reflects their higher rates of unemployment, lower incomes and poorer health. However, public tenants also appear to be less 'happy' with their circumstances and have less confidence in institutions such as the Australian parliament, Universities and the $\mathrm{ABC}$ (the public television broadcaster). Public tenants' lower levels of confidence in universities appear to suggest a failure to recognise the benefits of higher education, and lower levels of bridging 
social capital. These results probably reflect the residualised nature of public housing in Australia, which is increasingly targeted at the most disadvantaged citizens. Our results suggest that public tenants are likely to be 'alienated' from certain aspects of mainstream and elite culture although they share some institutional advantages and have higher levels of confidence in sections of the public service, defence forces and major Australian companies than private renters or homeowners. The finding that social housing tenants express different levels of confidence in certain institutions even controlling for a range of social background factors is important in terms of policy debates about the relationship between public housing and social disadvantage.

It is possible that public housing tenants' levels of social capital may reflect the personal characteristics of the economic classes and income levels of citizens who live in public housing. However, Woods (2002) suggests that the erosion of mainstream services is a common theme reported in Australian public housing case studies. The lack of private services reduces the potential for public tenants to maintain or develop new external social networks associated with bridging social capital. Local shops, banks and business are often boarded or closed in public housing areas so local residents feel abandoned and mistrustful. Levels of morale and self-esteem can be fragile due to poor police response times, limited property maintenance by budget strapped public housing authorities and a lack of public transport. Larger public housing estates can make it more difficult for residents to form and maintain external relationships and a feeling of isolation will erode social capital. However, public housing can 'shore up' confidence and social capital in some areas, which suggests that levels of trust would be even lower if public housing was not available (Flint and Kearns, 2006: 41).

Kearns and Parkinson (2001) claim that residents in disadvantaged communities often engage in high levels of mutually supportive behaviour and tend to develop bonding social capital, due in part to the discrimination and exclusion they experience outside their community. Bonding capital enables members of a disadvantaged community or ethnic group to pull together in order to 'get by'. So when a marginalized population is concentrated in public housing they are likely to develop a kind of local dependence upon one another, which could be at odds with the established political and institutional order. The downside to this form of bonding is that the sense of community solidarity and reciprocal norms can work to limit an individual's capacity to identify or engage with people who are regarded as 'different', in other words it can create a sense of 'otherness' or social exclusion.

The task of promoting higher levels of social capital and public participation in disadvantaged public housing neighbourhoods is not straightforward. The responses of Australian public tenants suggest that the concentration of disadvantaged households fosters a culture of stigmatization and public tenants feel the need to overcome their 'housing commission' label (Wood, 2002: 5-6). The stigma associated with public housing tenure can lead to discrimination in the employment market and restrict access to finance. Narrow social networks reduce the flow of information; while lower levels of social capital increase transaction costs and limits employment opportunities, which in turn can undermine self-esteem (Wood, 2002: 6).

\section{Conclusion}

In Australia, trust is generally higher among the tertiary educated, the self-rated middle classes and those on higher incomes. Slightly higher levels of trust are also apparent among men compared to women and those living in urban rather than regional and rural locations (Tranter and Skrbis, 2009). Although public housing tenants have access to secure and affordable housing, they are less trusting and exhibit less confidence in some government institutions such as the Australian parliament and $\mathrm{ABC}$ (the public television broadcaster) than homeowners.

Generally public housing tenants and private renters express lower levels of trust in public institutions even controlling for social background factors than homeowners. This is important because it suggests that renting as a form of tenure in some ways may exacerbate the disadvantage of citizens. Public housing is targeted at the most disadvantaged members of the community and they tend to have lower incomes, poorer health and lower levels of formal education than private renters or homeowners. However, our findings suggest that public tenants have more confidence in the defence forces and trade unions than private renters or homeowners. While private renters and homeowners have higher levels of confidence in Universities that suggests a stronger recognition of the benefits of higher education than public tenants.

\section{References}

1. Agresti, A. and B. Finlay (1997), Statistical methods for the social sciences (3rd ed.), Upper Saddle River, New Jersey: Prentice Hall.

2. Australian Institute of Health and Welfare (AIHW) (2010), A profile of social housing in Australia, Cat. no. HOU 232, Canberra: AIHW. 
3. Atkinson, R. and K. Jacobs (2008), Public housing in Australia: Stigma, home and opportunity, Housing and Urban Research Unit, Hobart: University of Tasmania.

4. Bourdieu, P. (1986), "The forms of capital”, In John G Richardson (Ed.), Handbook of theory and research for the sociology of education, New York: Greenwood Press.

5. Burstrom, B. and P. Fredlund (2001), "Self-rated health: is it a good predictor of subsequent mortality among adults in lower as well as in higher social classes?", Journal of Epidemiology and Community Health,55(11): 836-840.

6. de Vaus, D. (2002), Surveys in social research ( $5^{\text {th }}$ ed.), Crows Nest, New South Wales: Allen and Unwin.

7. Flint, J. and A. Kearns (2006), "Housing, neighbourhood renewal and social capital: The case of registered social landlords in Scotland", European Journal of Housing Policy, 6(1): 31-54.

8. Fukuyama, F. (1995), Trust: social virtues and the creation of prosperity, New York: Free Press.

9. Furedi, F. (2005), Culture of fear: Risk-taking and the morality of low expectation, London and New York: Continuum.

10. Gibson, R., S. Wilson, D. Denemark, G. Meagher and M. Western (2004), The Australian survey of social attitudes, 2003, Canberra: Australian National University.

11. Giddens, A. (2000), “Can we trust?", In D. Gambetta (Ed), Trust: making and breaking cooperative relations, Oxford, UK: Department of Sociology, Oxford University.

12. Goot, M. (2002), "Distrustful, disenchanted and disengaged? Public opinion on politics, politicians and the parties: An Historical Perspective", In D. Burchell \& A. Leigh (Eds.), The prince's new clothes, Sydney: UNSW Press.

13. Job, J. (2005), "How is trust in government created? It begins at home, but ends in the parliament", Australian Review of Public
Affairs, 6(1): 1-23.

14. Jones, A., R. Phillips and V. Milligan (2007), Integration and social housing in Australia: challenges and options, Queensland Research Centre, AHURI Positioning Paper No. 102.

15. Kearns, A. and M. Parkinson (2001), "The significance of neighbourhood", Urban Studies, 38(12): 2103-2110.

16. Long, J. (1997), Regression models for categorical and limited dependent variables, Thousand Oaks, CA: Sage.

17. Putnam, R. (1995), "Tuning in, Tuning out: the strange disappearance of social capital in America”, Political Science and Politics, 28(4): 664-683.

18. Putnam, R. (2000), Bowling alone, New York: Simon and Shuster.

19. Skocpol, T. (2003), Diminished democracy. From membership to management in American civic life, Norman, Oklahoma: University of Oklahoma Press.

20. Tranter, B. And Z. Skrbis (2009), "Interpersonal trust, institutional trust and confidence in significant others among young Queenslanders", Australian Journal of Political Science, 44(4): 659-678.

21. Tranter, B. (2007), "Political knowledge and its partisan consequences", Australian Journal of Political Science, 42(1): 73-88.

22. Troy, P. (2000), "Suburbs of acquiescence, suburbs of protest", Housing Studies, 15: 717-738.

23. Watt, P. (2006), 'Respectability, roughness and 'race': neighbourhood place images and the making of working-class social distinctions in London", International Journal of Urban \& Regional Research, 30(4): 776-797.

24. Wood, M. (2002), "Resident participation, social cohesion and sustainability in community renewal", Paper presented at the Housing, crime and stronger communities conference Sheffield, Urban Frontiers Program: University of Western Sydney. 